\title{
TEMPORAL EXTERNALISM, DEFERENCE, AND OUR ORDINARY LINGUISTIC PRACTICE
}

\begin{abstract}
Temporal externalists argue that ascriptions of thought and utterance content can legitimately reflect contingent conceptual developments that are only settled after the time of utterance. While the view has been criticized for failing to accord with our "ordinary linguistic practices", such criticisms (1) conflate our ordinary ascriptional practices with our more general beliefs about meaning, and (2) fail to distinguish epistemically from pragmatically motivated linguistic changes. Temporal externalism relates only to the former sort of changes, and the future usage relevant to what we mean reflects reason-driven practices that are rational for us to defer to.
\end{abstract}

A number of authors have recently defended a type of "temporal externalism" (hereafter TE) according to which, roughly, ascriptions of thought and utterance content can legitimately reflect contingent conceptual developments that were only settled after the time of utterance. There are different explanations of why this should be the case, with some taking what we mean to supervene at least in part upon our future usage, while others take such ascriptions to show that meaning does not supervene upon usage at all. ${ }^{1}$ Nevertheless, all versions of TE deny what I will here call 'presentism', namely, the view that what we mean by a term at a time necessarily supervenes upon our use up to that time. ${ }^{2}$ The response to TE has typically been little more than the proverbial incredulous stare, but Jessica Brown has progressed from the stare to actual criticisms of $\mathrm{TE}$, and the most serious of these relate to how TE supposedly "fails to

Pacific Philosophical Quarterly 86 (2005) 365-380

(C) 2005 University of Southern California and Blackwell Publishing Ltd. Published by

Blackwell Publishing Ltd, 9600 Garsington Road, Oxford OX4 2DQ, UK and

350 Main Street, Malden, MA 02148, USA. 
accord with our ordinary ways of assessing the truth value of utterances". ${ }^{3}$ However, it will be argued here that Brown's criticisms miss the mark, and that they do so primarily because (1) they fail to distinguish our ordinary ascriptional and evaluative practices from our more general beliefs about what sorts of things can affect what we mean, and (2) they fail to appreciate the extent to which the differences between current and future usage relevant to TE are driven by epsistemic factors. Consequently, if we wish to find a reason to reject TE, we need to look elsewhere.

The relevant differences between Brown and the temporal externalists show themselves in their analyses of cases such as the following. ${ }^{4}$ The term 'Grant's zebra' was introduced around 1820 for a type of zebra native to Kenya. A few years later, the term 'Chapman's zebra' was introduced for a morphologically distinct type of zebra found in present-day Zimbabwe. Later still it was discovered that the two types of zebra interbred near the Zambezi River and that, morphologically, one gradually faded into the other. Grant's and Chapman's zebras were thus both taken to be races of the species Equus burchilli. However, while that was how our usage of the term actually developed, it seems likely that if the taxonomists had investigated the area around the Zambezi River before they explored Zimbabwe, they would have "discovered" that Grant's zebra could be found through most of East Africa, gradually changing into a different subspecies as it drifted south. In this counterfactual scenario, 'Grant's zebra' would have been applied to the entire species, not just the race found in Kenya. (I will, following Brown, ${ }^{5}$ refer to 1820 in the actual case as ' $1820_{\mathrm{A}}$ ' and 1820 in the counterfactual case as ' $1820_{\mathrm{C}}$ '.) In neither case would the users of 'Grant's zebra' understand themselves as changing what they meant by the term over time. Consequently, such cases suggest that, when we interpret the past use of speakers (including ourselves), we help ourselves to subsequent specifications which were not determined by the facts available at, or before, the time of utterance. ${ }^{6}$

The view that we should endorse such "temporally loaded" ascriptions is admitted by most temporal externalists to be, at least initially, counterintuitive. Nevertheless, it has been argued that if one already accepted the sorts of "causal/historical" and "social" externalisms associated with Putnam's and Burge's work, there was little reason not to accept TE as well. ${ }^{7}$ Brown, by contrast, argues that there are good reasons to accept the more familiar sorts of externalism while rejecting TE. ${ }^{8}$ She not only questions the value of the increased continuity and determinacy of meaning that comes with TE, but also claims that, unlike the more familiar sorts of externalism, TE "fails to accord with our ordinary linguistic practice". ${ }^{9}$ The second of these two criticisms is the more central, but I'll discuss the two in order.

"Presentist" accounts of meaning and content, which treat 'Grant's zebra' as meaning the same thing in $1820_{\mathrm{A}}$ as it does $1820_{\mathrm{C}}$, suggest that the term's meaning was indeterminate in 1820, and changed as the more 
determinate meanings developed in the two possible futures. TE thus provides more continuity and determinacy of meaning than presentist accounts that take future usage to be irrelevant to meaning. In response to this, Brown points out that such increased determinacy and continuity of meaning is only an advantage if it accords with our intuitions about whether the terms in question have such stable and determinate meanings. ${ }^{10}$ Brown notes that for vague terms (like 'bald') or terms that have clearly changed their meaning over the last century (like 'gay'), it would be a disadvantage for any theory to claim that they had unchanging determinate meanings. ${ }^{11}$ Brown may be right about such cases, but, unlike the users of 'bald' or 'gay' respectively, the speakers in the scenarios that TE focus on do think of themselves as meaning something determinate, and don't think of themselves as having changed what they meant over time. This remains true even if they are aware that some aspects of their usage have changed. For instance, rather than viewing themselves as having gradually changed what they meant by 'Grant's zebra', speakers in $1820_{\mathrm{C}}$ will view themselves as having discovered that the population of Grant's zebras gradually lose the stripes on their feet as one travels south. Users of 'gay', on the other hand, are unlikely to think that over the last century we somehow discovered that we had been mistaken in applying the term to festive heterosexuals. As we shall see later in the paper, a temporally externalistic framework can distinguish cases where meaning is sensitive to future usage from those where meaning is indeterminate and/or changes over time, and the many cases (such as 'bald' or 'gay') that intuitively seem to involve indeterminacy and change of meaning can still be treated as such by the temporal externalist. ${ }^{12}$

Of course, the reasons associated with determinacy and continuity do not provide, on their own, compelling reasons of the sort that would allow the temporal externalist to simply thrust the burden of proof upon the presentist. However, temporal externalists typically argue that (1) we do make ascriptions of thought and utterance content in a temporally externalistic fashion, so that if TE is rejected, some principled reason should be given for doing so, and (2) a principled reason that doesn't also rule out more familiar sorts of externalism is surprisingly hard to find. ${ }^{13}$ Of course, such an attempt to thrust the burden of proof upon the presentist is justified only if our ordinary linguistic practices are actually in line with TE. It is, then, not surprising that Brown directs her most serious criticisms towards this assumption.

Brown summarizes this second and more serious line of criticism as follows:

It is a fundamental problem for TE that it fails to accord with our ordinary way of assessing the truth-value of utterances. Externalist theses are supposed to be theses about how our language actually works. So they are plausible only to the extent that they accord with 
ordinary linguistic practices. I suggest that this is why the classic defenses of externalism involve an attempt to show that externalism accords with the speaker's intentions and linguistic practices. For example, Burge defends his externalist thesis by appeal to the facts that we frequently use words in ascribing propositional attitudes to a speaker even if the speaker incompletely understands those words; that we view those who incompletely understand words as sharing concepts with those who fully understand them; and, that each of us defers to our community for the correct explication of the concepts involved in our thoughts (Burge, 1979, pp. 89-95). By contrast, we do not regard evidence about future practices as relevant to the meaning or truth-value of current utterances and thoughts. More fundamentally, we do not defer to future linguistic practice for the correct explication of our concepts. (Brown, 2000, pp. 186-7)

While Brown is right to claim that externalist theses get much of their appeal from their accordance with our linguistic practices, it is far less clear that TE fails to accord with our ordinary ways of assessing the truthvalue of utterances. We can't, after all, assess the truth-value of each others utterances without assigning truth-conditions to them, and our ordinary ascriptions of truth-conditional content seem manifestly to support TE in that they are often sensitive to linguistic developments that have taken place after the ascribed thought or utterance has occurred. ${ }^{14}$ (In what follows, I'll typically just refer to such ascriptions of truth-conditions and subsequent evaluations of truth-value as our "ascriptional practice".)

Admittedly, if the scenarios about which they are making their ascriptions are presented so that it is clear to ascribers that their ordinary ascriptions would commit them to TE, then they may be hesitant to make such ascriptions. However (and crucially), this shows more about our folk theories about what sorts of things are relevant to what we mean than it does about our ordinary ascriptional and evaluative practices. Indeed, if the scenarios associated with social externalism are presented in a way that a commitment to social externalism is made clear, people often become resistant to ordinary "social" ascriptions as well. People have a strong inclination to think that they must have the same mental states as their atom-for-atom duplicates, and they will often diverge from their ordinary ascriptions if they become aware that such accounts conflict with this intuition.

Because of this, when discussing "our ordinary way of assessing the truth-value of our utterances" we need to focus on cases that do not reflect such initial forays into theorizing. Unfortunately, Brown appeals to precisely such cases when she claims, for instance, that "The taxonomists in $1820_{\mathrm{A}} \ldots$ would hold that the truth value of 'Grant's zebra has striped feet' depends only on their intentions and practices with 'Grant's zebra' and the facts about zebra's". ${ }^{15}$ This is unobjectionable as a claim about how aspects of their folk semantic theorizing are incompatible with TE, but it does not show that their ordinary ascriptional or evaluative practice is also incompatible. ${ }^{16}$ After all, it is not unlikely that, if the question were 
suitably presented, a taxonomist of $1820_{\mathrm{A}}$ would claim that the truthvalue of his utterance of "Grant's zebra has striped feet" was independent of the sorts of social and historical factors Burge and Putnam appeal to as well. The thought experiments associated with semantic externalism typically have the function of highlighting how our actual ascriptional practices are out of line with our initial (typically individualistic) intuitions about meaning, ${ }^{17}$ and the types of cases used to motivate TE are no exception. Consequently, if one is already an externalist of the other sorts, the mere fact that TE is out of line with such "folk theoretical" commitments should not be viewed as a decisive objection to TE. ${ }^{18}$

A related point can be made about Brown's claim that "we do not regard evidence about the future practices as relevant to the meaning or truth-value of current utterances or thoughts". ${ }^{19}$ Understood as a claim about what we explicitly regard as relevant, Brown's claim may be true. If asked "do you regard evidence about future practices as relevant to the meaning of your current utterances" most people would say "no". (Brown captures this sense perfectly when she argues that the taxonomists in $1820_{\mathrm{A}}$ "would reject the claim that the truth-value of their utterance in $1820_{\mathrm{A}}$ depends on future linguistic practice". $)^{20}$ However, understood this way, Brown's point is, once again, not about our ascriptional practice but rather about a theoretical attitude we have regarding the sorts of things that could be relevant to meaning. Understood as a claim about what we implicitly regard as relevant, Brown's claim would be about our actual practices and attributions, but understood this way, it seems false. In our ascriptional practices we take what is, in fact, evidence about future practices as relevant to interpreting and evaluating our own thoughts. ${ }^{21}$ When we are presented with such evidence (usually over the passage of time), we treat it as relevant.

This leads directly to the question of whether or not we would "defer" to future usage in the way that we clearly do often defer to the usage of our contemporaries. I should note here that talk about "deferring to usage" may not be the best way to frame this issue. As will become clear, when we "defer to another's usage", we are deferring to the beliefs and the reason's behind that usage, not the usage itself. Still, since Brown initially presents the issue in terms of deference to usage, and so I'll initially present the issue in these terms as well. That said, Brown sees with the issue of deference another asymmetry between TE and more familiar forms of social externalism. Of course, given that future usage is found in the future, information about it typically is not accessible to us in a way that would make deference to it possible. ${ }^{22}$ However, Brown argues that even if we had evidence about future usage, we would have no inclination to defer to it. As she puts it: "even if such evidence were available, it is implausible that it would be used in assessing the current truth-value of utterances and thoughts". ${ }^{23}$ 
This seems far from obvious. For instance, if I could see into the future and discovered that a certain substance that scientists now call a 'protein' was no longer classified as a 'protein' by scientists three years from now, I would probably take it as evidence that that substance wasn't really a protein, and that current claims that it was must be false. ${ }^{24}$ It would be more plausible to think that biochemists had discovered something new about proteins (or the substance in question) than it would be to think that the scientific community would change what it meant by the term over the next three years. Usage is a product of both meaning and belief, so if usage changes, it may be explained either by a change of meaning or a change of belief. The question of whether or not we would defer to evidence about future usage can't be answered independently of the question of whether we would think that the differences between current and future usage resulted from a change of meaning or a discovery about the world. ${ }^{25}$ Our inclination to defer to future usage will be largely dependent upon our understanding of why the usage of a term has changed. ${ }^{26}$

In particular, we can distinguish pragmatic from epistemic explanations of linguistic change. "Pragmatic" theories explain change in terms of nonrational factors such as taboo, metaphor, semantic drift and the like. ${ }^{27}$ For instance, 'zipper' changes from being a brand name to a generic name for such mechanical fasteners because the brand is so successful that users of the language gradually forget that the items of that kind are ever called anything else. We have a sociological/psychological explanation of the change, but no justification in terms of the truth of the beliefs involved. By contrast, "epistemic" theories explain changes in usage in terms of factors such as the need to keep our beliefs consistent both with new experience and with each other. We stopped, say, applying the term 'fish' to whales because we discovered that whales were in many important respects closer to those creatures we called 'mammals' than to other creatures we called 'fish'. ${ }^{28}$ With this distinction between epistemic and pragmatic factors contributing to linguistic change in place, the following five points should be noted:

First of all, epistemic theories provide a kind of rational justification for the change that pragmatic theories do not. Epistemic theories are normative in the sense that they explain change in terms of what people rationally ought to believe. Epistemic accounts of linguistic change are closer to philosophical accounts of belief revision than they are to what one expects to find in books on historical linguistics. By contrast, pragmatic theories are descriptive in that they explain changes in usage over time by appealing to factors that typically produce such changes. For instance dominant brand names ('tabloid', 'cellophane', 'zipper', 'aspirin', 'escalator', 'granola', 'yo-yo', 'linoleum') often become generic terms for the products they are instance of. The change in usage is explained, but it is not, in the relevant (epistemic) sense, justified. That is to say, it 
is not shown that the set of beliefs reflected in the new usage is any better than the old..$^{29}$

Secondly, speakers are (unsurprisingly) disinclined to defer to the sorts of linguistic change that could be explained by pragmatic factors. Someone who does not use 'wean' as a synonym for 'rear' need not be impressed by any sort of pragmatic explanation of how 'wean' came to acquire its currently popular usage. On the other hand, if one had reason to think that future usage would be different from one's own based on (perhaps another's use of) an epistemic theory of linguistic change, then one might very well be inclined to defer to such usage. The theory predicts, after all, that one's current usage conflicts with some other aspect of one's usage that one is, or will be, committed to, and that such contradictions have been resolved in the altered usage. There is a clear sense that the new usage is an improvement, rather than just a change, and thus that there are good reasons to defer to it. Indeed, a failure to defer might seem perverse in that one is deliberately holding on to usage one knows to be inconsistent.

Admitedly, some people will alter their usage to correspond to changes that they know to be caused by pragmatic factors, because there are good pragmatic reasons for using one's terms as other do. We can thus distinguish "pragmatic" from "epistemic" deference depending on the type of factors that produced the usage deferred to. However, it is only in cases of epistemic deference that speakers will take their prior usage to be mistaken in the sense of involving false beliefs. In cases of pragmatic deference, speakers will see themselves as having meant something idiosyncratic by their terms rather than as having used a shared term incorrectly. ${ }^{30}$

Third, the sorts of linguistic development produced by epistemic factors are typically understood as resulting in a change in belief rather than changes to the meanings of the terms involved. A pragmatic theory explains why a term comes to be used differently, and so it shouldn't be surprising that such changes in usage should be associated with changes in meaning. In the historical linguists' pragmatically motivated cases, linguistic change is epistemically unmotivated, and the change may be from a pattern of usage that is perfectly consistent as it is. There was, for instance, nothing inconsistent in the older use of 'meat' to mean food more generically, and the term's current restriction to animal flesh did not follow from any sort of "epistemic" progress. (In much the same way, Brown's example of 'gay' is one where the change in use was clearly produced by pragmatic rather than epistemic factors.) On the other hand, the changes in usage associated with epistemic theories involve making the original usage more consistent (both with itself and with the environment), and there is a sense in which the new usage could be seen as already there "implicitly". Consequently, it isn't surprising that the sorts of changes explained by epistemic theories are not typically associated with changes of meaning. 
Fourthly, while Epistemic and Pragmatic theories can both be used to predict how the usage of others will change over the next few years, only pragmatic theories can be used to predict changes in the future of one's own usage. Epistemic theories can be used to make predictions about another's language, but when we apply them to our own language, they typically produce change rather than merely predicting it. ${ }^{31}$ For instance, a pragmatic theory might predict that, say, terms like 'Viagra', 'Prozac', and 'Rogain' will become generic terms. It might now be considered (strictly speaking) false to claim that one bought some 'Rogain' at the store if one just bought a knock-off, but one might predict that in a few years such usage will be correct. I can recognize that our usage might evolve this way, but I need have no inclination to defer to it. By contrast, if my epistemic theory predicted that we would stop calling sloths 'mammals' because they turned out to be, in spite of their fur, coldblooded egg layers, I would have good reasons to change my current usage as well, since the evidence for the change would be good evidence that sloths are not mammals. The sorts of things that would lead us to view a change in usage as a reflection of a discovery about the world rather than a change of meaning (discovered inconsistencies in current usage, or new information about the world) typically lead us to revise current usage rather than simply predict how usage would change in the future.

Consequently, if we acquire information about future usage that reflects changes produced by epistemic factors, it would come not from a theory produced by linguists, but rather from one produced by people studying those aspects of the world relevant to the terms in question. In the scenario described above, a scientist working on sloths might predict that our usage of 'mammal' would change so that the term would no longer be applied to sloths. In such a case, if the zoologist were to tell me that we would soon no longer be applying 'mammal' to sloths, I would take that as good reason to think that I had been mistaken in thinking that sloths were mammals. On the other hand, any realistic case where we see, based on a purely linguistic theory, a future use that is significantly different from ours would be one where the difference in question was produced by pragmatic factors. ${ }^{32}$

Fifthly, the cases of linguistic change associated with TE are all of the sort that are produced by epistemic factors, since TE relates to cases in which good epistemic reasons can be given to justify the changes of usage in question. ${ }^{33}$ The extension of the term 'Grant's zebra' to all of Equus burchilli after $1820_{\mathrm{C}}$ is justified by the fact that the initial sample of Grant's zebra was discovered to interbreed with the Zebras found further south, and by the prior belief on the part of the term's users that interbreeding was a criteria for kind membership. The change is produced because the users had good epistemic reasons to make it. Had they been presented with such justifications for the subsequent linguistic development, 
it does not seem implausible to think that the taxonomists in $1820_{\mathrm{C}}$ would defer to (the beliefs expressed by) such future usage. That is to say, if they were told that their utterance of "Grant's zebra has striped feet" was false because it was later discovered that the species extended down the continent and that some of the instances found in Zimbabwe lacked striped feet, they would probably accept such a correction. The usage of 'Grant's zebra' in 1820 incorporates a then unperceived instability that future usage is able to resolve.

Of course, in the cases associated with TE, more than one set of changes could resolve the instability within the initial usage, but such rationally underdetermined changes should not be assimilated to those changes of the sort studied by historical linguists where no epistemic (as opposed to pragmatic) justifications are given for the change at all. ${ }^{34}$ The fact that a change is underdetermined before it occurs doesn't alter the fact that it is produced by epistemic factors once it occurs. Consequently, unlike the sorts of change associated with pragmatic factors, the changes associated with the TE cases $d o$ represent an epistemic improvement over the (beliefs reflected by the) older usage. The fact that it may not be the only possible improvement over current usage doesn't change the fact that it is an improvement, or the fact that one has good reason to defer to it. ${ }^{35}$

In light of all this, Brown fails to address the real issue when she argues:

Suppose that linguists in $1820_{\mathrm{A}}$ had been studying linguistic change and had developed a well-supported theory about such change that predicts (as it happens incorrectly) that, at a latter time, 'Grant's zebra' will be applied to a number of morphologically distinct types of zebra. If TE is correct, then such a prediction would constitute strong evidence against the truth of the taxonomist's utterance [of "Grant's zebra has striped feet"] by providing evidence that the utterance amounts to the claim that all zebras have the particular morphological feature of striped feet. But, it seems highly implausible that they would regard such evidence as even relevant to the truth of their utterance. Instead, they would regard this evidence as pointing to a future change in meaning. (p. 186)

It is hard to deny that such taxonomists would react as Brown suggests. However, this point is of questionable relevance because, contrary to Brown's supposition, the case is not one of the sort relevant to TE. After all, a "well supported theory of linguistic change" with predictive power would almost certainly be one that dealt with change caused by "pragmatic" factors. ${ }^{36}$ Consequently, while it wouldn't be the sort of theory that deals with changes that we need (epistemically) defer to, it also wouldn't be a theory that deals with the sort of cases that TE is concerned with.

In short, Brown's claim that we would not defer to future usage seems to rely on understanding linguistic change as produced exclusively by pragmatic factors, and thus ignores the fact that we often have good reasons for changing how we use our terms, and that (like other sorts of externalism) TE relies on this epistemic aspect of our evolving linguistic practice. 
At this point, some might object that, even if the subject would defer to (the beliefs expressed by) future usage in the cases associated with TE, she would only do so because she takes facts about the world to be so relevant, not because she takes facts about future linguistic usage per se to be relevant to the current meaning, and hence truth-value, of her utterance. Now there is both a short and a long response to this worry.

The short response is that this complaint simply recapitulates the problems with Brown's original objection, since it presents a worry about the subject's intuitive judgments about what sorts of things are relevant to what they mean as if it were one about their everyday practice. The issue here is about whether we would defer to future linguistic usage in the sorts of cases TE focuses on, not about why we would. Of course it is open to critics of TE to argue that, even if we would defer to future usage in such cases, given that how to best resolve our current inconsistencies is underdetermined, we shouldn't defer to such usage. However, that is not the subject of Brown's (or this) paper, which is whether or not TE "fails to accord with our ordinary linguistic practice". Whether our ordinary practice should remain in accord with TE is another matter. ${ }^{37}$

The future usage that TE takes to be relevant to what we mean is restricted to that usage which reflects epistemic improvements to our web of belief, and while Brown claims that "It is a serious objection to TE that if fails to accord with our ordinary linguistic practice", ${ }^{38}$ what TE has actually been shown to conflict with are our naïve intuitions about what sorts of things could be relevant to what we mean. When Brown brings up "our ordinary linguistic practice" she typically ends up talking about such naïve intuitions, and her objections thus ultimately amount to another way of saying that TE is, as was never denied, "unintuitive". This is not to deny that an adequate account of meaning should be sensitive to both our intuitions and our ordinary ascriptional practices, ${ }^{39}$ only to insist that at least as far as the ordinary ascriptions go, TE is in good shape.

That said, it may be worth adding a few words about the larger worry behind the "we don't see ourselves as deferring to usage per se" intuition. Part of what lies behind this worry is that, when we form our beliefs, we don't think of our central interests as being linguistic. We want to find out how things are in the world, not just how some other person uses her words. ${ }^{40}$ To put the worry another way, when we defer to a person we take to be authoritative, we defer to what she believes or claims about the world, not just her usage. This point is true enough, and seeing why it doesn't apply to TE should help make it clearer just what the Temporal Externalist is claiming.

First of all, we should note that we can see a version of this worry in some responses to social externalism, where social deference is understood as deference to usage per se. Of course such pragmatically motivated deference does occasionally occur; I may, for instance, stop calling my 
pants 'pants' (rather than 'trousers') if I find myself in England. However, when such pragmatic deference occurs, it shows nothing about what I meant before. Critics of social externalism, such as Davidson and Bilgrami, often seem to understand all social deference on this pragmatic model, where people are simply deferring to the various sorts of prestige associated with (or local prevalence of) various linguistic groups, not the reasons behind their usage. ${ }^{41}$ It is not surprising, then, that they don't take social usage to be relevant to what our terms mean. ${ }^{42}$

Fortunately for the social externalist, most cases of deference are not best understood on this "pragmatic" model. We don't simply defer to social usage per se; we take the experts to know more about the world than we do, and it is to this world-based expertise that we are ultimately deferring to. Furthermore (and crucially), people are often correct to think this about expert usage. In such cases of epistemic deference, we are not deferring to usage per se, but rather to the reasons behind the usage. (While in cases of pragmatic deference we are just deferring to the usage itself.)

In much the same way, TE does not take linguistic usage per se to be relevant to what we mean. ${ }^{43}$ TE takes meaning to be a reflection of an ongoing reason driven practice that includes future usage. It is a mistake to consider such usage in isolation as if it were that that determined what we meant. If that were the case, it wouldn't matter if the differences between current and future usage were produced by pragmatic or epistemic factors. Rather, information about linguistic usage reflects epistemic commitments that are relevant. In the cases we are considering, we are not deferring to usage simply as usage (in the way that some might defer to high prestige pronunciation simply because it is high prestige pronunciation). There are good reasons behind the altered usage in the cases associated with TE, and it is to such reasons, not just the usage itself, that we ultimately defer. The fact that speakers would take such future change to be motivated by facts about the world is not, in itself, a problem for TE, since TE applies only in cases where we are correct in thinking that the changes are motivated this way. This would not be the case if TE were committed to changes produced by pragmatic factors also being read back into earlier contents, but as should be clear by now, the view involves no such commitment. Our usage is the product of our beliefs, and in deferring to future usage, we are deferring to the beliefs and judgments behind it. ${ }^{44}$

In conclusion, if linguistic changes are epistemically driven, future users can be said to know more about the world than we do in virtue of having a more expansive and consistent worldview, so in the cases that TE applies to, we are deferring to facts about the world. No one argues that social deference is rendered irrelevant by the fact that people defer to expert usage because they take it to be motivated by facts about the world, and no one should argue against TE this way either. ${ }^{45}$ In both cases, the criticism would only be legitimate if (as with the pragmatic cases or with 
deference to pronunciation) people were wrong to take expert or future usage to be so motivated. However, with both TE and various forms of social externalism, ${ }^{46}$ we are right to think that the usage we are deferring to is epistemically superior to our own. After all, experts typically do know more about (the relevant portions of) the world than we do, and in the sorts of cases that the temporal externalist focuses on, future communities can claim a similar sort of epistemic privilege. Deferring to future usage is deferring to the practice that such usage embodies, and that practice is driven by reasons. ${ }^{47}$

\section{Department of Philosophy \\ York University Toronto}

\section{NOTES}

A view of the former sort seem to be defended most explicitly in Jackman, 1999, while a view of the latter seem most clearly articulated in Ebbs, 1997, 2000 (who also attributes the former type of position to Wilson, 2000). Lance and O'Leary-Hawthorne, 1997 also seem to defend a version of TE more sympathetic to the later explanation (see, esp. pp. 196-7). A commitment to varieties of TE can also be found in Koethe, 1982, and Rouse, 1987. The fact that we make such temporally loaded content ascriptions is noted, but not endorsed, in Wilson, M., 1982, Donnellan, 1983 and Sorensen, 1997. Something like TE is also defended, but not necessarily endorsed, in Stoneham, 2003.

2 There are both individualistic and non-individualistic varieties of presentism, depending upon whether "our use" is understood distributively or collectively.

3 Brown, 2000, p. 186. Jackman, 1999 is Brown's explicit target, though her criticisms, if good, should be equally telling against any of the other authors mentioned above.

4 The case is discussed in Brown, 2000, and is adapted from Jackman, 1999 and ultimately from Wilson, 1982 (who elaborates on a case from Mettler and Gregg, 1969).

5 Brown, 2000, p. 181.

6 I am assuming here that the introducers of the term would not have considered that its morphological and interbreeding criteria might come apart, and so would have formed no clear intention about which criteria to favor if they were discovered to do so. Consequently, as she suspects (p. 184), the sorts of cases Brown discuses on pp. 182-3, where the introducers of the term have already considered this possibility (or at least formed a clear intention applicable to it), are not relevant here. Cases involving such determinate intentions typically would, according to the framework outlined in Jackman, 1999, be ones where one's current usage "settled" what one's terms referred to independently of any future practices.

7 See, for instance Ebbs, 2000, pp. 247, 252; Jackman, 1999, p. 173; Lance and O'LearyHawthorn, 1997, p. 79, who all seem to argue that a proper understanding of Putnam, 1975 and Burge, 1979 strip away any commitments incompatible with TE.

8 I should note here that TE admits of both individualistic and non-individualistic formulations. The former allows only the speaker's own future behavior to be relevant to what she currently means, while the latter also takes into consideration to future behavior of the speaker's community. Brown's characterization and discussion of TE identifies it with its stronger non-individualistic formulation (p. 187), and since that also seems to be the version that most interests the authors her criticisms apply to, I will only discuss the stronger formulation here. 
9 Brown, 2000, p. 187. Brown also notes that: (1) while I endorse TE about both meaning and thought content, most of my arguments focus on meaning, and (2) I don't show why TE must also be true of content just because it is true of meaning. This point is fair enough, and I try to motivate such a transition (in somewhat tedious detail) in Jackman, 2003.

${ }^{10}$ Brown, 2000, p. 179.

${ }_{11}$ Though some would deny that this is the case for vague terms. Indeed defenders of "epistemic" theories of vagueness (e.g. Sorensen, 1988, 2001; Williamson, 1992, 1994) argue that there are very good reasons to think that our vague terms must have, in spite of the appearances to the contrary, determinate extensions. I think that such epistemicists about vagueness actually have good reasons to be temporal externalists, but it is far less clear that all temporal externalists should be epistemicists. (See Jackman, 2004 for an extended discussion of these issues.)

12 The issue is discussed at some length in Ebbs, 2000, 2002; Jackman, 1999, Lance and O'Leary-Hawthorn, 1997, and the upcoming discussion of deference in terms of epistemic vs. pragmatic reasons for linguistic change.

${ }^{13}$ Simply asserting that TE is, say, "an outrageously bizarre view of language" (Donellan, 1983 , p. 103) does not amount to providing such a principled reason. Donnellan actually has in mind here the view that the "psychological quirks" of future users could affect what we currently mean. Nevertheless, he goes on to claim that any view that made meaning sensitive to the sort of "historical accident" characteristic of the 'Grant's zebra' case would be "just as bizarre" (p. 104). Donellan's remarks come in the context of a discussion of Putnam, 1975, and I should note that, while Brown argues that its future directedness makes temporally externalistic conception of linguistic practices noticeably different from that associated standard externalist thought experiments (p. 180), TE can be understood as an elaboration on Putnam's aside that language use often involves a "division of linguistic labor across time" (Putnam, 1975, p. 229). Indeed, Ebbs (1997, pp. 212-15) seems to interpret Putnam, 1975 as endorsing some version of TE all along, and Lance and O'Leary-Hawthorn (1997, p. 196) find a similar commitment in Putnam, 1988.

${ }^{14}$ The ordinary description of the 'Grant's zebra' case is a clear instance of this, and such cases are often associated with any expansion of our worldview. (For a discussion of this, see Wilson, 1982, p. 572; Sorensen, 1997, pp. 363, 372, and for the suggestion that Locke held something like this view, see Shapiro, 1999.)

15 Brown, 2000, p. 186. Grant's Zebra all have striped feet, while other varieties of Equus burchilli do not, so according the to T-externalist, the claim would be true in 1820a, but false in $1820 \mathrm{c}$.

16 Of course, we may ultimately be justified in revising aspects of our ordinary ascriptional practice because of how they conflict with such "theoretical" intuitions. (Indeed, some (e.g. Bilgrami, 1992; Davidson, 1994) would argue that we should ultimately take this revisionary attitude towards the ordinary practices that support social externalism as well.) However, such revised ascriptions should not be presented as if they had been characteristic of our "ordinary" ascriptions all along.

17 This seems true not only in the historical development of accounts of meaning from Locke to the present day, but also in (as far as I can tell) the sorts of theories students initially develop when presented with the question of what determines the meaning of their terms.

${ }^{18}$ For a discussion of this, see Ebbs, 2000, p. 262.

19 Brown, 2000, p. 187.

${ }^{20}$ Brown, 2000, p. 186, italics mine. They might, however, still regard evidence about future usage as relevant to the truth-value of their claims, since it is not unreasonable to take the differences in that future practice to reflect discoveries about the world.

${ }^{21}$ Thanks for Lionel Shapiro for helping me clear up some of the formulation in this area. 
22 Some might thus wonder whether we could really form any clear idea of what we would do, if we could, say, see into to the future. Consequently, the fact that we ascribe current meanings to the past strikes me better support for TE than any speculation on whether or not we would defer to the future. Still, Brown seems to think that it is fairly clear that we wouldn't defer in such cases, and I'm concerned here with defending TE against this claim. Further, there are non-fantastic cases were we could have good evidence about how future usage would be develop, and two varieties of these will be discussed in the second half of this paper.

${ }^{23}$ Brown, 2000, p. 187.

${ }^{24}$ I'm not suggesting that 'protein' need be a term for which TE is true, only that, if it were available, we often would take evidence about future usage as relevant to the evaluation of the truth of our own judgments. That is, such commonplace cases suggest that it simply isn't the case that "even if [evidence about future usage] were available, it is implausible that it would be used in assessing the current truth-value of utterances and thoughts".

${ }^{25}$ Or, in Quine's terms, whether it comes from a change of meaning or a change of belief. We should also be wary of whether there is a sharp line between these two. (For a discussion of how such Quinean considerations relate to Brown's criticisms of TE, see Stoneham, 2003.)

${ }^{26}$ Precisely the same question arises, of course, with whether we would defer to social usage. If we think that the difference in usage results from a difference of meaning (as we sometimes do), we will not be inclined to defer.

${ }^{27}$ For a discussion of some of these see Hock, 1991.

28 Though this was not, of course, the only way that this tension in our prior use could have been resolved. For a discussion of this see Jackman, 1998, 1999.

${ }^{29}$ Indeed, the usage may in some respects be inferior to that of the old. For a discussion of how usage produced by such pragmatic changes may be retrograde, see Dummett, 1993.

${ }^{30}$ In these terms, the main difference between writers like Burge and Davidson is that the former treats social deference as being epistemic, while the later treats it as being pragmatic. When deference is pragmatic, there is no reason to think that there is any incompatibility between the beliefs of those involved, while when deference is epistemic, such an initial conflict seems present.

31 There will be some cases where this may not occur, as when the speaker is trying to misinform his audience and so holds on to the usage that he now takes to be faulty.

${ }^{32}$ Linguistic terms of art such as 'noun', 'phoneme' being partial exceptions to this, in that epistemic changes would be produced by what is still recognizably a "linguistic" theory. Still, it would not be a linguistic theory of the sort that is typically used to explain linguistic change.

${ }^{33}$ That is to say, the change resolves unperceived inconsistencies in the current use rather than mere practical inconveniences in speaking a certain way.

${ }^{34}$ Note that while there may be two possible ways of making the usage coherent, only one path may have been open to the actual future, and if determinism is true, only one way is really possible. We could have developed another way to make things consistent, in just the sense that we could have been in a community that used their terms differently.

35 In those cases associated with TE, two or more possible avenues of change can each be considered rational, and it is only the current usage that is inconsistent. The future speakers have good reasons for speaking the way they do, and the fact that another possible future could have reasons for speaking differently is no more relevant than the fact that another possible present community could have reasons for using, say, 'arthritis' differently. Further, one should also note that we defer to experts in various fields now even if their current usage was not strictly determined by how the terms in questions were used in the past. 
${ }^{36} \mathrm{I}$ 'm assuming that Brown does not have in mind well supported theory of linguistic change of the following epistemic sort: "When people discover that a term of theirs does not apply correctly to a range of cases, they try to stop applying it in those cases", or "if people discover that their use of a term is inconsistent, they change it to make it consistent". If that were the sort of theory we had in mind, then it would seem foolish not to defer to its results.

${ }^{37}$ And I argue for a positive response in Jackman, 1996, 1999.

${ }^{38}$ Brown, 2000, p. 187.

${ }^{39}$ For a recent discussion of this interplay, see Devitt, 1996. The topic of whether an acceptable equilibrium between our intuitions and practices would still endorse such ascriptions is a separate and important question. I argue for a positive answer to it in Jackman, 1996, 1999.

${ }^{40}$ I owe this formulation of the worry to an anonymous referee of an earlier version of the paper.

${ }^{41}$ See, for instance Davidson, 1994, Bilgrami, 1992. Davidson seems to read all social externalism on the model of his understanding of Kripke's reading of Wittgenstein (Kripke, 1982), where social usage provides a norm for individual usage simply because the individual does defer to the group with no suggestion that the social usage has any advantage over individual use other than that it is the usage that has been adopted by the most people. (Though for a possible change of heart, see Davidson, 2003.)

${ }^{42}$ Davidson seems to understand deference on a "syntactic" model. Since each adult's syntax is perfectly complete, there is no objective sense in which one person's syntactic usage is better than anyone else's, so anyone's deference to another's usage must be the product of merely pragmatic factors.

${ }^{43}$ Since much linguistic change is motivated, but not strictly determined, by the facts about the world, responding to the change is not simply responding to "linguistic change per se" (as it would be if one were responding to simple semantic drift), nor is it simply responding to the world (since there is more than one type of change compatible with the world in this way). (For a related discussion, see Stoneham, 2003.)

44 'Use' should thus be understood in a suitably "thick" sense where the entire temporally extended linguistic practice is reflected in it. Future usage is only relevant to what we mean if it can be understood as part of the same practice as our current usage, and it is only epistemically driven changes that preserve a practices identity over time.

${ }^{45}$ For a discussion of this, see Burge, 1989.

${ }^{46}$ But not all. The type of social externalism associated with Kripke, 1982 (especially Davidson's reading of it) often seems to suggest that social usage per se is all that matters, even if there are no reasons behind it.

${ }^{47}$ Thanks to Gary Ebbs, Sanford Goldberg, Lionel Shapiro, Tom Stoneham, audience members of the 2003 Central Division Meeting, and an anonymous referee from this journal for comments on earlier versions of this paper.

\section{REFERENCES}

Bilgrami, A. (1992). Belief and Meaning. Cambridge: Blackwell.

Brown, J. (2000). "Against Temporal Externalism," Analysis 60, 2, pp. 178-88.

Burge, T. (1979). "Individualism and the Mental", in French, Uehling \& Wettstein (eds.), Midwest Studies in Philosophy IV: Studies in Metaphysics. Minneapolis: University of Minnesota Press, pp. 73-121.

Burge, T. (1989). "Wherein is Language Social?", in A. George (ed.), Reflections on Chomsky. New York: Blackwell. 
Davidson, D. (1994). "The Social Aspect of Language", in McGuinness and Oliveri (eds.) The Philosophy of Michael Dummett, Dordrecht: Kluwer.

Davidson, D. (2003). "Responses to Barry Stroud, John McDowell and Tyler Burge", Philosophy and Phenomenological Research vol. LXVII, 3, pp. 691-99.

Devitt, M. (1996). Coming to Our Senses. New York: Cambridge University Press.

Donnellan, K. (1983). "Kripke and Putnam on Natural Kind Terms", in Ginet and Schoemaker (eds.) Knowledge and Mind. New York: Oxford University Press, pp. 84-104.

Dummett, M. (1993). Grammar \& Style. London: Duckworth.

Ebbs, G. (1997). Rule-Following and Realism. Cambridge: Harvard University Press.

Ebbs, G. (2000). "The Very Idea of Sameness of Extension Across Time", American Philosophical Quarterly 37, 3, pp. 245-68.

Ebbs, G. (2002). "Learning from Others", Noûs 36, 4, pp. 525-49.

Field, H. (1973). "Theory Change and the Indeterminacy of Reference", The Journal of Philosophy LXX, 8, pp. 462-81.

Hock, H. H. (1991). Principles of Historical Linguistics, $2^{\text {nd }}$ edition. New York: Mouton de Gruyter.

Jackman, H. (1996). Semantic Norms and Temporal Externalism. Ph.D. Thesis, University of Pittsburgh.

Jackman, H. (1998). "James' Pragmatic Account of Intentionality and Truth", Transactions of the C. S Peirce Society Winter 1998, XXXIV, 1, pp. 155-81.

Jackman, H. (1999). "We Live Forwards but Understand Backwards: Linguistic Practices and Future Behavior", Pacific Philosophical Quarterly 80, pp. 157-77.

Jackman, H. (2003). "Expression, Thought and Language", Philosophia 31, 1-2, pp. 33-54.

Jackman, H. (2004). "Temporal Externalism and Epistemic Theories of Vagueness", Philosophical Studies 117, 1-2, pp. 79-94.

Koethe, J. (1982). "The Stability of Reference Over Time", Noûs 16, 2, pp. 243-52

Kripke, S. (1982). Wittgenstein on Rules and Private Language. Cambridge: Harvard University Press.

Lance, M. and O'Leary-Hawthorne, J. (1997). The Grammar of Meaning. New York: Cambridge University Press.

Mettler, L. and Gregg, T. (1969). Population Genetics and Evolution. Englewood Cliffs: Prentice Hall.

Putnam, H. (1975). "The Meaning of 'Meaning'”, in H. Putnam Mind Language and Reality. New York: Cambridge University Press, pp. 215-71.

Putnam, H. (1988). Representation and Reality. Cambridge, MA: MIT Press.

Rouse, J. (1987). Knowledge and Power. Ithaca: Cornell University Press.

Shaprio, L. (1999). "Towards 'Perfect Collections of Properties': Lock on the Constitution of Substantial Sorts", Canadian Journal of Philosophy 29, 4, pp. 551-93.

Sorensen, R. (1988). Blindspots. Oxford: Clarendon Press.

Sorensen, R. (1997). "The Metaphysics of Precision and Scientific Language", Philosophical Perspectives, 11, Mind, Causation, and World, pp. 349-74.

Sorensen, R. (2001). Vagueness and Contradiction. New York: Oxford University Press.

Stoneham, T. (2003). "Temporal Externalism”, Philosophical Papers 32, 1, pp. 9-107.

Williamson, T. (1992). "Vagueness and Ignorance", Proceedings of the Aristotelian Society, Supp. Vol. 66, pp. 145-62. (reprinted in Keefe and Smith, 1996a.)

Williamson, T. (1994). Vagueness. London: Routledge.

Wilson, G. (2000). "Satisfaction Through the Ages", in Kanamori (ed.) Proceedings of the Twentieth World Congress of Philosophy, Volume 6: Analytic Philosophy and Logic. Bowling Green: Philosophy Documentation Center.

Wilson, M. (1982). "Predicate Meets Property", The Philosophical Review XCI, 4, pp. 549-89. 